\title{
Physician assistants in English primary care teams: A survey
}

\author{
Vari M. Drennan ${ }^{1}$, Kaushik Chattopadhyay ${ }^{2}$, Mary Halter ${ }^{1}$, Sally Brearley ${ }^{1}$, Simon de Lusignan ${ }^{3}$, \\ Jonathon Gabe ${ }^{4}$ and Heather Gage ${ }^{3}$ \\ ${ }^{1}$ Faculty of Health and Social Care Sciences, St. George's University of London \& Kingston University, London, UK, ${ }^{2}$ Kings College \\ London, London, UK, ${ }^{3}$ University of Surrey, Guildford, UK, ${ }^{4}$ Royal Holloway, University of London, Egham, UK
}

\begin{abstract}
Ensuring that healthcare teams have a mix of skilled professionals to meet patient needs and deliver safe and costeffective services is a major imperative in all health services. The health services in the UK, like a number of other countries, have been exploring the contribution that physician assistants (PAs) can make to healthcare teams including primary care. PAs are well established in the USA, where they have a recognized qualification and undertake physical examinations, investigations, diagnosis, treatment and prescribing within their scope of practice as agreed with their supervising doctor. The first UK-trained PAs graduated in 2009 from post-graduate courses, which are modeled closely on those in the USA to a UK agreed set of competencies and curriculum. There is evidence of the substantive employment of PAs in primary care teams in England. The UK has a well-developed primary care system, with most care delivered via general practice teams which generally include a mix of medical, nursing and support staff. The extent of the employment of PAs in primary care in the England and their contribution within the team to patient care is unknown. This paper reports on a survey that investigated these questions.
\end{abstract}

Keywords: Interprofessional care, physician assistants, primary care teams, survey

\section{INTRODUCTION}

Ensuring that healthcare teams have a mix of skilled professionals to meet patient needs and deliver safe and cost-effective services is a major imperative in all health services. The health services in the UK, like a number of other countries, have been exploring the contribution that physician assistants (PAs) can make to healthcare teams including primary care (Farmer, Currie, Hyman, West, \& Arnott, 2011). PAs are well established in the USA, where they have a recognized qualification and undertake physical examinations, investigations, diagnosis, treatment and prescribing within their scope of practice as agreed with their supervising doctor (Mittman, Cawley, \& Fenn, 2002). The first UK-trained PAs graduated in 2009 from postgraduate courses, which are modeled closely on those in the USA to a UK agreed set of competencies and curriculum. There is evidence of the substantive employment of PAs in primary care teams in England (Drennan, Levenson, Halter, \& Tye, 2011). The UK has a well-developed primary care system, with most care delivered via general practice teams which generally include a mix of medical, nursing and support staff (Shaw, de Lusignan, \& Rowlands, 2005). The extent of the employment of PAs in primary care in England and their contribution within the team to patient care is unknown. This paper reports on a survey that investigated these questions.

\section{METHOD}

An electronic anonymous, self-completion survey was designed and piloted with two UK PAs who had previously but were not currently working in primary care. Electronic invitations to participate were sent to PAs known to be working in general practice in England via the UK Association of Physician Assistants (UKAPAs), course leaders of three English PA courses and PAs identified in previous research (Drennan et al., 2011) in October 2010, with onward snowball sampling. At that time, UKAPA estimated that about 25 PAs were working in primary care. The survey questions focused on (a) the activities and role of PAs in the primary care team, (b) employment setting and (c) professional qualifications. The survey did not require National Health Service (NHS) ethical review and fulfilled all university requirements for the ethical conduct of research. Descriptive analysis of the data was undertaken using a statistical package.

Correspondence: Vari M. Drennan, Faculty of Health and Social Care Sciences, St. George’s University of London \& Kingston University, Grosvenor Wing, St. George’s, Cranmer Terrace, London, SW170RE, UK. E-mail: V.Drennan@sgul.kingston.ac.uk

(Received 15 February 2012; revised 16 April 2012; accepted 16 April 2012 ) 
Table I. Reported clinical activities by PAs in primary care teams.

\begin{tabular}{|c|c|c|c|}
\hline Type of activity & $\begin{array}{l}\text { Number of } \\
\text { respondents }\end{array}$ & $\begin{array}{l}\text { Median number of hours spent/week } \\
\text { (interquartile range) }\end{array}$ & $\begin{array}{c}\text { Range of number of patients seen/hour } \\
\text { ( } n=\text { number of respondents })\end{array}$ \\
\hline $\begin{array}{l}\text { Booked surgery (same day/urgent } \\
\text { face-to-face appointments) }\end{array}$ & 12 & $16.5(7.8-27.5)$ & 3 to more than $12(n=11)$ \\
\hline $\begin{array}{l}\text { Booked surgery (general/non-urgent } \\
\text { face-to-face appointments) }\end{array}$ & 12 & $8(7.0-14.3)$ & 3 to more than $12(n=11)$ \\
\hline Test results' review & 10 & $3(1.0-4.0)$ & 4 to more than $12(n=3)$ \\
\hline $\begin{array}{l}\text { Booked surgery (chronic disease management } \\
\text { face-to-face appointments) }\end{array}$ & 7 & $4(3.0-5.5)$ & 2 to $6(n=7)$ \\
\hline Telephone advice/booked consultations & 4 & $2(1.8-2.5)$ & 2 to $3(n=3)$ \\
\hline Telephone triage & 2 & $8(4.5-11.5)$ & Unspecified to more than $12(n=1)$ \\
\hline Other patient care activities & 9 & $4(3.0-6.0)$ & 1 to more than $12(n=4)$ \\
\hline
\end{tabular}

\section{RESULTS}

Sixteen PAs working in primary care returned the survey: giving an estimated response rate of $64 \%$. There were missing data in four survey responses. Half the respondents $(n=8)$ were graduates of UK PA courses and half of USA courses. Fourteen respondents reported employment in general practice: three of these also worked in walk-in-centers, urgent care and primary care out-of-hours services. Two respondents had worked in the same general practice for over 5 years but most had worked for less than that. Eight respondents worked in settings described as urban and deprived, two in urban non-deprived and two in rural areas. The general practices ranged from a patient list of under 3000 to over 20,000. Two respondents worked in practices that employed no nurses but eight respondents reported working in general practices that also employed nurse practitioners. Nine respondents reported working in practices that employed salaried doctors and three respondents worked in practices that had only partner general practitioners (GPs). The most frequently reported clinical activity and the highest in time spent, was seeing patients in booked surgery appointments, both for same day/urgent and non-urgent appointments (Table I). The next most frequently reported activity was test results review, followed by booked appointments for chronic disease management with patients. The other patient care activities included minor surgery (e.g. cryotherapy), home visits, answering patient queries and administrative paperwork, each reported by a small number of PAs. Reported broader responsibilities included teaching, audit and supervision of healthcare assistants.

\section{DISCUSSION}

This study indicates that there is a small number of PAs working within primary care teams in England. The teams they work in vary from single-handed GPs (solo practice) to teams consisting of multiple groups of professionals including salaried doctors, nurses and nurse practitioners. While the PAs report a broad range of patient-focused activities, the survey suggests a sizeable element of their work is in providing same day/urgent consultation appointments for patients in primary care. This concurs with information provided by a small number of employing GPs 2 years previously (Drennan et al., 2011) and with reports of the acute (but relatively minor) workload of PAs in general practice in the Netherlands (Simkens, van Baar, van Balen, Verheij, van den Hoogen, \& Schrijvers, 2009).

This study has limitations in that it has an estimated 64\% response rate and is a self-report, rather than externally verified, survey. However, it provides an insight not provided elsewhere into the participation of a new professional group within the primary care health team and their contribution to patient care in England. A subsequent survey of UK PAs (Ritsema \& Patterson, 2011) indicates similar numbers working in primary care but provides little detail of their contribution to the primary care team and patient care. This quantitative, self-report survey did not illuminate issues such as interprofessional relationships and these require different methodologies such as observation and qualitative interviewing.

\section{CONCLUSION}

This study provides evidence of a new group of professionals, PAs, working in English primary health care teams and contributing to a range of patient care but focused in particular on same day and urgent consultations. The scope of this survey is limited and more detailed questions remain as to the patient and professional responses to a new professional group within English primary care. These are currently under investigation in the phase two of the study.

\section{ACKNOWLEDGMENTS}

Our thanks to the participating PAs and those who helped us contact them. This survey is part of a study funded by the National Institute for Health Research (NIHR) Service Delivery and Organisation (SDO) program (09-1801-1006). The views and opinions expressed herein are those of the authors and do not necessarily reflect those of the NIHR SDO program or the Department of Health.

\section{Declaration of interest}

The authors report no conflicts of interest. The authors alone are responsible for the content and writing of the paper. 


\section{REFERENCES}

Drennan, V., Levenson, R., Halter, M., \& Tye, C. (2011). Physician assistants in English general practice: A qualitative study of employers' viewpoints. Journal of Health Service Research \& Policy, $16,75-80$.

Farmer, J., Currie, M., Hyman, J., West, C., \& Arnott, N. (2011). Evaluation of physician assistants in National Health Service Scotland. Scottish Medical Journal, 56(3), 130-134.

Mittman, D.E., Cawley, J.F., \& Fenn, W.H. (2002). Physician assistants in the United States. British Medical Journal, 325(7362), 485-487.
Ritsema, T., \& Patterson, K. (2011). Physician assistants in the United Kingdom: An initial profile of the profession. Journal of the American Association of Physician Assistants, 24(10), 1-4.

Shaw, A., de Lusignan, S., \& Rowlands, G. (2005). Do primary care professionals work as a team: A qualitative study. Journal of Interprofessional Care, 19(4), 396-405.

Simkens, A.B.M., van Baar, M.E., van Balen, F.A.M., Verheij, R.A., van den Hoogen, H.J.M., \& Schrijvers, A.J.P. (2009). The physician assistant in general practice in the Netherlands. Journal of Physician Assistant Education, 20(1), 30-38. 